\title{
Differences of factors influencing the volleyball teaching effect
}

\author{
Pengcheng Li \\ Institute of Physical Education, Jiangsu Normal University, Xuzhou 221116, China
}

\begin{abstract}
According to the influence of volleyball passing the success rate of experimental data, to establish statistical model of the influence factors of the existing research, find out the key factors, and through the crowd of like volleyball and I don't like volleyball, find out the main factors of the development of volleyball. By analytic hierarchy process (AHP), the analysis of the four main factors influencing the volleyball passing technique: the fingers and wrists elastic, passing sharpie law, goal setting, the main factors affecting the volleyball passing shot, and puts forward corresponding Suggestions on volleyball passing skills.
\end{abstract}

\section{Introduction}

Evaluate volleyball pass success rate, it should consider volleyball players' finger flexibility and wrists elastic force, coaches' pass teaching method, objective setting and volleyball types as well as other multiple problems. From the perspective of volleyball athlete finger flexibility and wrists' elastic force, generally speaking, volleyball is a kind of motion technique that makes use of whole body coordination strength meeting the ball through finger and wrist elastic force [1-3]. If fingers are not flexible enough or arms strength is quite small, it will largely reduce pass success rate. From the perspective of coach pass teaching method, in modern society, volleyball teaching methods have important effects on volleyball promotion, and similarly to pass teaching methods that also have important effects on pass success rate [4].

Therefore, with regard to affect pass factors finger flexibility and wrists' elastic force, pass teaching method, objective setting as well as volleyball types these four elements establish model to carry out research, analyze and find out each factor whether is important or not, meanwhile implement difference test on volleyball pass success rate affected decisive factors, and make corresponding suggestions.

\section{Statistics model establishment and analysis}

This paper utilizes SPSS software, carry out statistical analysis of previous volleyball pass success rate influence factors experiments, and further get each influence factor increasing volleyball techniques aspects [5].

\subsection{Fingers flexibility and wrists' elastic force effects on pass technique}

According to one university students fingers flexibility and wrists' extension items experimental data, from which two classes are random selected and beginners, also no great remarkable differences in technical levels. Experimental group introduces training aids to classroom teaching and lets passers' fingers flexibility and wrists' elastic force get further strengthen, control group is the class without adding fingers flexibility, wrists' elastic force training in teaching, through statistics handling, and then it can get experiment data [6]. It is clear that experimental class compares with control class, technical evaluation performance has very remarkable differences, and control class pass success rate is $7 \%$ lower than that of experimental class. Therefore, pass technique through finger flexibility and wrist elastic force training and motions seizing status are helpful for volleyball pass technique and motions' seizing, suggests that it is done in volleyball course.

\subsection{Coach pass teaching method effects on pass technique}

According to the university 2012 grade volleyball general course students about coach pass teaching method affects pass technique influences' data to carry out analysis, from which two classes are random selected and beginners, it also has no significant differences in technical levels. Except for pass teaching method is different, experimental group and control group both adopt same syllabus, same schedule, of course same teachers have same numbers of students. Experimental group adopts representation

a Corresponding author: PengchengLi@sina.com 
training method, induction, limit method and transformation method to implement teaching practice; and using volleyball pass teaching steps, method and other teaching ways in teaching are control group adopted main methods [5]. By statistics, it handle with experimental data (as Table 1 showed results)

Table 1. Pass four technical linkages' technical evaluation performance test.

\begin{tabular}{|c|c|c|c|c|c|}
\hline Group type & Numbers of people & Shift and take location & Hitting point & Hand type & $\begin{array}{c}\text { Coordinate to } \\
\text { exert }\end{array}$ \\
\hline Experimental group & 15 & 4.5 & 4.1 & 3.9 & 4.1 \\
\hline Control group & 15 & 4.3 & 4.0 & 3.3 & 3.7 \\
\hline$T$ & & 0.85 & 0.85 & 4 & 3.25 \\
\hline$P$ & & $>0.05$ & $>0.05$ & $<0.01$ & $<0.01$ \\
\hline
\end{tabular}

Table 2. Experimental group and control group standard results' test.

\begin{tabular}{|c|c|c|c|c|c|c|}
\hline Group type & $\begin{array}{c}\text { Numbers of } \\
\text { people }\end{array}$ & $\bar{x}$ & $S$ & $S_{D}$ & $T$ & $P$ \\
\hline Experimental group & 15 & 4.5 & & & & \\
\hline Control group & 15 & 3.1 & 0.24 & 0.46 & 3.043 & $<0.01$ \\
\hline
\end{tabular}

Through comparing Table 2 data, make comparison among pass 4 technical linkages, it is clear that experimental group gets relative higher scores than control group, experimental group pass hand type, mutual coordination abilities' differences are quite remarkable, and with regard to shift and take position as well as hitting point, experimental group compares with control group, their differences are not significant. Therefore, in volleyball technique teaching process, applying experimental group adopted teaching method possesses significant propelling effect.

\subsection{Objective setting effects on pass technique}

According to the premise that the university use regular method teaching in 2012 grade, make statistical analysis of experimental data about objective setting affects pass technique, from which two classes are random selected and beginners, it has no significant differences in technical levels. Except for objective setting is different, both experimental group and control group adopt same syllabus, same schedule, of course same teachers has same teaching quantities. Experimental group concrete flow about objective setting roughly is first, set key objective, make preparation for start transferring positive attitudes. In normal status, hitting position, hand type and other three linkages aspects generate main influences on teaching merits. In future teaching, it can carry out according to operation steps. Control group then carry out regular method teaching according to teaching syllabus. After statistics handling, it can get experiment data.

Through Table $3 X^{2}$ test, it is clear that $P<0.05$, therefore, it is known that experimental group standard result success rate is higher than that of control group, experimental group is even more helpful for volleyball pass technique improving, so it suggests that teaching department should focus on objective setting teaching.

\subsection{Volleyball types effect on pass technique}

Carry out analysis of the university 2011 grade volleyball students' volleyball types affect pass techniques' influence data, from which two classes are random selected and beginners, it has also no remarkable differences in technical levels. Except for objective setting is different, both experimental group and control group adopt same syllabus, same schedule, of course same teachers has same teaching quantities. From which experimental group adopts balloon volleyball to carry out teaching, control group adopts hard volleyball to carry out teaching. After handling by statistics, it can get experiment data (experiment results details can refer to Table 4).

Table 3. Two group students' front overarm pass standard result success rate comparison.

\begin{tabular}{|l|c|c|c|c|c|c|c|}
\hline Group type & $\begin{array}{c}\text { Numbers of } \\
\text { people }\end{array}$ & $\begin{array}{c}\text { Teaching time total } \\
\text { score }\end{array}$ & $\begin{array}{c}\text { Total } \\
\text { times }\end{array}$ & $\begin{array}{c}\text { Success } \\
\text { times }\end{array}$ & $\begin{array}{c}\text { Success rate } \\
(\%)\end{array}$ & $X^{2}$ test & P \\
\hline Experimental group & 30 & 125 & 150 & 107 & 71 & 551 & $<0.05$ \\
\hline Control group & 33 & 150 & 165 & 89 & 54 & & \\
\hline
\end{tabular}

Table 4. Experimental class and control class performance comparison table.

\begin{tabular}{|c|c|c|c|c|c|c|}
\hline Group type & Numbers of people & $\begin{array}{l}\text { Teaching time total } \\
\text { score }\end{array}$ & Total times & Success times & Success rate (\%) & $P$ \\
\hline Experimental group & 30 & 125 & 100 & 87 & 87 & $<0.05$ \\
\hline Control group & 33 & 150 & 95 & 40 & 42.1 & \\
\hline
\end{tabular}


Table 5. Restrict human select volleyball as body building investigation report (multiple choice).

\begin{tabular}{|c|c|}
\hline Numbers of people & 250 \\
\hline School volleyball is hard volleyball & 152 \\
\hline Teaching plan is dull & 93 \\
\hline Teaching objective is not clear & 50 \\
\hline Course selection conflict & 140 \\
\hline Lack of interests & 53 \\
\hline
\end{tabular}

From Table 4, it is clear that experimental class technique evaluation performance compares with that of control class $(P<0.05)$, differences are not remarkable; Control class performance is 44.9 percentages far lower than that of experimental class. Therefore, when teaching, adopt soft volleyball is more helpful for seizing volleyball pass technique and motions.

\subsection{Investigation that restricts human select volleyball as body building}

Restrict human select volleyball as boy building's investigation objects are from the university nearby university students (investigation report refers to Table 5).

By Table 5 human select volleyball body building restricted investigation report, maximum restrict students volleyball selection numbers of people is that school volleyball is hard volleyball (total 152 people), the next is teaching plan is dull and poor finger flexibility and wrist elastic force as well as failed in test (respectively are 152 people and 140 people), course selection conflict and teaching objective is not clear, lack of interests as constraints are only 26 people. It can see from that, when present university students select sports course, the more care is how to complete learning and body building purposed on the premise of relaxing, or to say is that they care for completing learning plans, to students, they are seriously lack of interests, therefore, teachers should strengthen volleyball advertisement and encouragement in class or daily advertising, make clear teaching plans, if possible, it might as well adopt soft volleyball teaching.

\section{Analytic Hierarchy Process (AHP) establishment and analysis}

\subsection{Model establishment}

Based on above data, for finger flexibility and wrist elastic force training, adopt multiple methods( representation method, induction method, limit method, transformation method and other pass methods) as well as objective setting method teaching, soft pass these four influence factors to establish hierarchical analysis model.

Considering comparison matrix 1-9 scale, as well as each variable measurement standard is different, it can define weight of each factor got data as $\{3,5,5,8\}$, its scale is $\{1,2,2,5\}$.

Carry out solution on model establishment defining criterion layer weights on target layer comparison matrix formula (1), solve feature value from matrix theory as $\begin{array}{lllll}8.2430 & 340+1.3315 \mathrm{i} & 0.0340- & 1.3315 \mathrm{i} & -0.0451+0.4407 \mathrm{i}\end{array}$ $-0.0451-0.4407 \mathrm{i}$, so matrix A maximum feature root is $\lambda=4.2430$.According to simple type hierarchical analysis method theory, $w$ is criterion layer weights on target layer, the bigger weight is representing the bigger influence factors would be. Therefore, volleyball pass success rate influence ranks from biggest to smallest in successive are soft volleyball, adopt multiple pass methods (representation training method, induction method, limit method, transformation training method etc.), setting method teaching, finger flexibility and wrist elastic force training.

\subsection{Consistency judgment}

In evaluation process, evaluators is impossible to correct define all value factors, according to existed errors extents differences, further cause different feature value matrix deviation defining. In construct judgment matrix process, it isn't required judgment matrix has very high consistency extent, only requires that judgment matrix roughly be consistent, otherwise analyze cannot be done. Therefore, firstly it should solve maximum feature root $\lambda$, then can carry out consistency test. Concrete steps are as following: When $C R<0.1$, it is thought that judgment matrix consistency can be acceptable, $C R>0.1$, then it is not conform to consistency requests, it requires to revise the judgment matrix again, keep consistency. And by calculation, it is clear that $C R=\frac{C I}{R I}=\frac{0.0347}{0.89}=0.03820<0.1$, so feature vector $w$ accordingly be regarded that target layer hierarchical weight is reasonable.

\section{Conclusions}

Utilize volleyball pass teaching assistant training induction teaching method is effective and easy operating, which plays great roles in improving students' pass process coordinate exertion and finger elastic force improving. Multiple teaching ways provide advanced teaching ways transfer teaching, make up for traditional teaching shortcomings, increase participating students' positivity and sense of liability, and strengthen students understanding on knowledge, reveal things essence, convert abstract into concrete is helpful for teaching process optimization.

In volleyball course, objective setting teaching method is worthy promoting and applying. By investigation, it can know university students' volleyball development restricted factors are mainly volleyball type objective setting, students in learning process have no bigger interest factors, the key is whether can complete learning 
task or not.

\section{References}

1. Y. Zhang and H. T. Sun, Journal of Shenyang Normal University, 25, 523-526 (2007).

2. J. Q. Chen, Journal of Yunnan University, 10, 2011.

3. X. B. Deng, Journal of Nanjing Institute of Physical Education, 6, 39-41(2007).

4. Y. Zhang, Journal of Chengdu University, 21, 51-55(2002).
5. S. S. Park, Y. T. Rhim and M. J. Kim et al, Journal of Coastal Research, 72, 96-100(2014).

6. W. Z. Lu, Journal of Nanjing Institute of Physical Education, 1, 49-51(2002).

7. Z. F. Qi, G. S. Wang and N. S. Charistos, Journal of Mechanical Engineering Research and Developments, 39, 315-323(2016). 